\title{
What We Can Learn from Pilots for Handovers and (De)Skilling in Semi-Autonomous Driving: An Interview Study
}

\author{
Sandra Trösterer*, Alexander Meschtscherjakov*, Alexander G. Mirnig*, Artur Lupp*, \\ Magdalena Gärtner", Fintan McGee ${ }^{+}$, Rod McCall ${ }^{+}$, Manfred Tscheligi ${ }^{*}$, Thomas Engel ${ }^{\mathrm{x}}$ \\ *Center for Human-Computer \\ Interaction, University of \\ Salzburg, Austria \\ \{firstname.lastname\}@sbg.ac.at \\ ${ }^{\mathrm{x}}$ Interdisciplinary Centre for \\ Security, Reliability and Trust, \\ University of Luxembourg, \\ Luxembourg \\ thomas.engel@uni.lu
}

\begin{abstract}
In aviation, pilots interact with autopilots almost on a daily basis. With semi-autonomous vehicles, this is not yet the case. In our work, we aimed at finding out what we can learn from pilots' current experiences for the domain of autonomous driving and what implications can be derived. We conducted three in-depth interviews with pilots to investigate how pilots currently handle handover situations to and from the autopilot, which information is relevant for this transition to be successful, how pilots react in critical situations, how handovers are trained, and how flying and handover skills are maintained. We compare the gained insights with the domain of autonomous driving and reflect on implications for handovers and (de)skilling. Our findings suggest that the AUI community can learn from aviation in areas such as situation awareness, transparency of system status, the need for a primary drive display, calibrated (dis)trust, and driver training.
\end{abstract}

\section{Author Keywords}

Pilots; handovers; autopilot; autonomous driving.

\section{CCS Concepts}

- Human-centered computing Empirical studies in HCI.

\section{INTRODUCTION}

Research on the topic of autonomous driving has strongly advanced in recent years. Apart from the focus on technological developments enabling autonomous driving, new research areas have evolved. These areas include the handling of semi-autonomous cars, communication with other road users, and general effects of autonomous driving with regard to drivers' skills or situation awareness (e.g., [8,

Permission to make digital or hard copies of part or all of this work for personal or classroom use is granted without fee provided that copies are not made or distributed for profit or commercial advantage and that copies bear this notice and the full citation on the first page. Copyrights for thirdparty components of this work must be honored. For all other uses, contact the Owner/Author.

AutomotiveUI '17, September 24-27, 2017, Oldenburg, Germany (C) 2017 Copyright is held by the owner/author(s).

ACM ISBN 978-1-4503-5150-8/17/09.

https://doi.org/10.1145/3122986.3123020
13, 24]). However, the large-scale employment of autonomous vehicles (according to SAE-Level 3 and above [23]) in the real world is still future work. Hence, actual experiences of drivers are difficult to capture at the current state.

In contrast, the use of autopilot systems is almost routine in the aviation domain for many years. Hence, pilots' daily experiences with autopilot systems may serve as valuable input when it comes to the design of transition systems for the automotive domain. In particular, the gained insights could help to inform the design of handovers (i.e., the transition of control between the driver and the car) and awareness systems regarding the current situation when taking over control. Furthermore, pilots' actual training practices could help to identify challenges with respect to the education of future drivers of semi-autonomous cars.

In this paper, we want to examine the following questions of what can be learned from the current use of autopilot systems in the aviation domain for the domain of autonomous driving and what implications can be derived for design in the automotive domain? In order to reach our goal, we conducted an interview study. Within the study, the following questions were of particular interest:

- How do pilots currently interact with the autopilot?

- How do pilots handle routine and critical handover situations?

- How do pilots train for flying and handover maneuvers?

Based on the interviews with three pilots (two of which are flight instructors), we provide insights on how handover situations to and from autopilot systems are currently handled in planes and how deskilling is counteracted. Based on the findings, we derive and discuss (design) suggestions for handovers and (de)skilling in the domain of autonomous driving. 


\section{RELATED WORK}

Ackermann et al. [1] state in their work, that there are two factors leading to a significant increase in research focusing on achieving safe and effective interaction between humans and automation systems. One factor was the implementation of high level automatization features in airplanes with the addition of complicated flight management interfaces called glass cockpits. These glass cockpits are usually equipped with a primary flight display (PFD), an instrument dedicated to visualize crucial flight information to the pilot. The second factor was the mistrust pilots had towards the automated systems $[15,16]$. Decades of research and the effort of designing and implementing better flight automation systems have been made by analyzing reaction times when switching from autopilot to manual controls [7] or by looking into the workload of the whole plane crew, as well as the situation awareness and physical design space in planes $[9,11]$.

Even with that much of research progress, it is still a problem to achieve an efficient and safe integration of pilots and automation systems [12, 14]. A lot of aviation accidents are the result of a variety of problems, usually caused by automation systems, pilots, or both [18].

Pilots are humans and humans make mistakes. However, a mistake while flying a plane may cost a lot of lives. Air France Flight 447 [6], for example, fell into the Atlantic Ocean, killing the entire crew and all passengers due to failing automation systems. Salomon et al. [17] analyzed the accident and concluded that it was the sociotechnical system that compromised aircrew and cockpit, as well as, airplane systems that lost situation awareness; it was not the fault of the aircrew alone. Failed handovers from automation system to pilots may cause accidents as well. For example, American Eagle Flight 4184 in 1994 [19] encountered in-flight icing which lead to loss of control and a failed handover situation, as the automation system failed to provide adequate information to the pilots concerning previously known effects of freezing precipitation on the plane.

It is a huge problem if pilots are not able to comprehend the displayed information and actions of automation systems in planes. The accident of Scandinavian Airlines Flight 751 [10] was caused by inadequate instructions and inspection routines. One routine was to ensure that clear ice is removed from the wings of an aircraft prior to takeoff. In this case, the ice broke off and was ingested by the engines, leading to engine surging. Additionally, the pilots were not trained to identify and correct engine surges.

On one hand, it seems that planes are automated so well that little skill is necessary to control them in the first place, so long as the automation system is working. On the other hand, only pilots who comprehend airplanes and the controls in their whole complexity are able to handle the plane if a complex handover situation arises. New approaches try to improve the quality of automation systems by making the autopilot system smarter by learning and imitating human pilots [3], by improving the glass cockpit with new ways of displaying relevant flight information to the pilot [2], or by handling human factors problems with automation systems [4].

In summary, many problems in aviation are caused by the handover situation from autopilot to manual flying; the same applies to automated driving. Even when the handover routine seems to be trivial for either the autopilot system or the pilot, small mistakes or errors during the process may lead to dangerous situations.

Young et al. [22] looked into aviation automation and tried to transfer important design philosophies to driving automation. They noted that when focusing on automation within the car domain, hard automation (i.e., the automation system will overrule the driver, if the driver exceeds the vehicle protection envelope) presents more problems than advantages. This is, due the different levels of automation, which offer different levels of protection depending on the contexts the driver has to be aware of, especially if mode changes are automatic.

Van der Meulen et al. [21] compared driving performance after parking with the performance after handover from autonomous mode. They concluded that there was no major difference in driving performance after the handover. However, participants paid more attention to the road during autonomous mode than on a distracting video that was played alongside the simulator task.

Results from a self-reporting questionnaire study by Trösterer et al. [20] suggest that mechanical driving skills are mostly retained even after longer periods of inactivity, automation assisted, or fully automated driving. It is doubtful whether the same can be said about situational awareness (SA), an essential requirement for safe and effective control transitions [24]. According to Gugerty [25], SA is lower when not in active control of a vehicle, thus causing potentially unsafe conditions for responding to transition requests.

\section{METHOD}

We conducted interviews with three male pilots. Two of them were also flight instructors. Two of the pilots were from Austria, the other one from Luxembourg.

Interviews were semi-structured and consisted of different topic groups. The first was concerned with the pilot's job outline and experience. The second dealt with the use of the autopilot and handover situations. This topic group comprised questions regarding, e.g., how a typical handover situation from autonomous mode to manual control looks like, which information is relevant for the handover, where to find the relevant information, or how pilots react in case of an unplanned handover. The third topic group was concerned with learning, deskilling, and trainings, focusing on, e.g., if and how handover situations are practiced, or which flying skills are likely to be unlearned without 
training. The interview was concluded with questions concerning, e.g., changes of flying skills due to the use of autopilots and what the area of autonomous driving could learn from automated flying.

The guideline for the semi-structured interviews was developed by two researchers in an iterative process. Based on our three main research questions, the topic groups and subsequently the interview questions were defined. The initial version was then further iterated and refined based on the feedback of members of our research group. The interview guideline was prepared in German and was further translated to English to allow conducting the interviews in the respective mother tongue of the pilots.

Two researchers conducted the interviews with the pilots. Each in-depth interview lasted between 1.5 and 2 hours. For analysis, interview notes and audio-recordings were transcribed. The interview data was then clustered and categorized following a thematic analysis approach [4]. Thereby, different themes emerging in each topic group were identified and summarized. Note, that the statements of the pilots were complementary in almost all cases, i.e., there was a strong agreement between the three pilots.

\section{Participants}

Pilot 1 was an Airline pilot and also working as a flight instructor for eight years in addition to his job as pilot (i.e., he conducted training courses). In regard to working time, he is working 700 block hours a year. Thereby, a block hour is considered as the time from when the plane begins rolling until coming to a complete stop. Fifty percent of his working consisted of the instruction of training courses. He primarily provided trainings for Airbus 320 . His main tasks as a flight instructor include regular checks of Airline pilots, education and training exercises in the simulator with emphasis on specific problems such as engine failures, and line training and line-checks, where the normal routine work of pilots is reviewed. Pilot 2 had been working as pilot for 12 years and was flying 650 block hours, primarily short distance flights within Europe. He was primarily flying Dash-840. Pilot 3, who also was a flight instructor, had been flying for 20 years. His real aircraft and simulated aircraft was a Boeing 737-800s. He was working 750 block hours.

\section{RESULTS}

In the following section, we address the most important findings gained from the interviews with respect to pilots' interaction with autopilots, routines for handover situations, and the role of pilot training.

\section{General Usage of Autopilots}

"Generally, it is very good that we have an autopilot. Flying eight hours straight can be done better by the autopilot than me." As outlined by all interviewed pilots, the autopilot is on almost the entire time during a scheduled flight. When the autopilot is switched on, it automatically flies the predefined route, makes curves, and regulates itself. Usually, it is switched on shortly after the start (approx. 1-3 minutes) and is also switched off rather shortly before the landing ( 3 minutes on average; subjective estimate of pilots; time may vary more in reality). Flying in automated mode happens approximately $95 \%$ of the time. Landings could be done automatically as well, but certain requirements need to be fulfilled, which are often not provided, e.g., an appropriate runway. It also needs a certain distance to the plane ahead, which is often a capacity problem for airports. Automatic landings are mainly completed when there is heavy fog and the sight is very bad. Generally, pilots must always have oversight and maintain awareness when the autopilot is on. They are fully responsible.

\section{Different Modes to Interact with Autopilots}

In the aviation domain, the used autopilot systems strongly differ. The design of the airplanes has a significant impact on the autopilot design. Airbus use an approach known as fly-by-wire, in which pilot interactions with the controls are passed to a computer which then makes the changes to the airplane configuration. There is no direct connection between the controls and the airplane components (aileron rudder etc.) In the alternative approach used by the Boeing airplanes the controls used by the pilot are directly connected to the components that they control (although the connection is mechanically assisted). These differences are also reflected in the autopilot functionality and implementations. Also, the systems of Airbus and Boeing use different modes for certain actions, such as descent. Thereby, an important aspect is that pilots need to know what is behind these modes in order to correctly operate the aircraft. In the aviation domain, this is not as easy because the systems can be quite complex. Furthermore, there are "different ways to tell the autopilot what to do." One way, is to make a certain selection, e.g., "fly to the right by 10 degrees" or "descend with a certain descent speed", which is taken over by the autopilot. The other way is that the flight management or onboard computer shall take over most parts, i.e., this is programmed while the plane is on the ground. The former way reflects a more direct approach, where only particular settings are made (comparable to changing speed settings when using cruise control in the car). In the latter case, the system is set to fully take over all necessary actions, which would be comparable to preparing a car for an autonomous drive. When modes are changed, the pilot and first officer are required to confirm actions verbally. They must follow the standard operating procedure, "select, verify, and call out." Mode changes are entered in the Flight Mode Annunciator.

\section{Cognitive Abilities}

In our interviews, the pilots agreed that plain manual steering is hardly unlearned, even if not flying for a while. It's similar to "You'll never forget how to ride a bike." However, cognitive abilities may be affected because manual steering draws more capacity. That is, orientation skills, the planning of what comes next, and if an additional 
error occurs, the recognition and correct evaluation of this error might become more difficult.

Orientation skills mean an understanding of how the plane flies in the 3-dimensional space. Planning refers to the scheduling of a flight, thereby specifically taking into account energy management or preparing certain actions (e.g., lowering speed before extending the landing flaps). "Simply put - in a jet you need to be mentally one minute ahead of the plane. I need to know now, which state - for example height or speed - I want in one minute."

\section{Training of Autopilot Usage}

The autopilot is also used quite often in the simulator. "You should use it, because you need to exercise and train for the different modes you can give the autopilot. For example, if you have an engine failure directly at the start, you need to exercise how to operate the autopilot correctly in that case. There are many trainings where we let the automatic system successively fail or induce errors."

\section{Monitoring the Autopilot and Foresighted Thinking}

As stated by the pilots, the working autopilot is monitored regularly during a flight, i.e., checked in regular intervals whether it flies in the wanted direction. If there is a deviation, many warning possibilities are available that automatically indicate that there is a deviation (e.g., if the plane leaves a certain altitude, there is a threshold, where the plane would report it). How regularly the autopilot is checked depends on its mode - if it is fed with certain settings (e.g., fly with a descent rate of 2500 feet), it needs to be checked more often compared to when it is set for cruise flight.

The behavior of the autopilot is frequently compared with the flight plan. Generating the flight plan is a part of the flight preparation on the ground. The flight plan is comparable to a motorway network and the flight streets pilots plan to fly are put in the onboard computer. The air traffic control also receives this plan. For all points on the route, pilots calculate how long they will need, which altitude they should fly, how much fuel they should have spent, etc. The printed flight plan is available on a clipboard for comparison (i.e., during the flight, the status of the plane is compared with what the pilots have on paper). That is, if the estimates do not correspond, there is probably something wrong.

While pilots can potentially do other things while the autopilot is on (like, e.g., eating, reading the newspaper, talking to colleagues, or performing routine activities), one thing remains important during the entire time: "You always must have a plan - What do I do if? You need to have alternatives if something is not working properly." This is particularly important for long-distance flights, where nearby airports may not be available. Pilots need to be concerned about, e.g., which weather conditions are to be expected or which runways are available. Pilots need to have a concept in advance. "Foresighted flying needs to occur permanently, even if the autopilot is on."

Primary Flight Display (PFD) and Flight Mode Annunciator (FMA)

In the cockpit, pilots have one instrument - the primary flight display (PFD) - available that summarizes the most important information and allows them to check, e.g., the altitude and status of the plane with (quasi) one glance. Note that, of course, other displays might be of relevance in a certain situation). In the center of the PFD, the most important instrument, the artificial horizon, is placed. The artificial horizon displays the current attitude, the nose, and bank attitude. This is particularly helpful when, e.g., flying in clouds where little orientation is possible. Furthermore, the PFD comprises of a speed indicator, an altitude indicator, slip-indicator, and the direction. Checking the PFD occurs very quickly, without the need to gather the relevant information across the cockpit. The scanning of the PFD happens between artificial horizon and the surrounding elements back and forth. This scanning pattern is also trained, so that pilots have a dab hand at it.

Before taking over from the autopilot, pilots also consider the Flight Mode Annunciator (FMA). The FMA indicates the different modes of what the automatic system is doing in that moment. This is particularly important because, even if the autopilot is switched off, some modes of the automatic system may still be active. The FMA is usually an LCD screen in a position of prominence.

\section{Trainings and Checks}

Training of pilots is a widely-spread field, and there are different kinds of trainings that pilots must pass through. Generally, there is a differentiation between trainings in the simulator and scheduled flights under supervision. Regarding simulator sessions, an accomplished airline pilot must undergo so-called "prof-checks and refresher-checks" every year. Proficiency-checks are official exams, while refresher-checks provide more freedom and enable to practice actions more creatively.

Pilots training comprises of different aspects. One thing is the technical operation of a "healthy" plane and how to use the different modes right. Furthermore, the outage of different systems (e.g., hydraulic system, flight control system), and operation of these in order to manage, needs to be practiced. Pilots must recognize errors (e.g., when a certain system fails) and handle them correctly, proving that they can deal with them in the right way. The different automatic systems in the plane have error recognition functionality, i.e., if an error occurs, it is displayed what is not working. Furthermore, it is automatically indicated, which checklist needs to be done and how the error should be handled. Pilot trainees are tested on their task sharing ability and for the level of oversight they have and conformance to standard operations. 
Furthermore, the manual operation of the plane, manual steering, and basic navigation (i.e., pilots need to interpret the needles on their own and build a 3-dimensional image in their head for orientation in the attitude and need to navigate accordingly) are practiced.

\section{Learning and Unlearning}

Generally, the selection of who is placed in a cockpit is a crucial factor in the aviation domain. A very good basic education, as well as a good spatial orientation ability are extremely important. Especially, when it comes to flying by instrument (i.e., not referring to the view outside of the airplane), basic navigation is important, i.e., the path has to be found solely based on the navigation instruments. This is one of the most difficult things to learn during training, as well as combining it with advance planning. Pilots must have anticipatory skills; otherwise, they would not accomplish the education.

According to the interviewed pilots, the technical operation of the plane and errors is rather easy to learn, because most pilots have a technical qualification and technical operations can be completed with checklists. For example, pilots have a laminated sheet for normal flight procedure, or a reference book for technical errors. Furthermore, pilots frequently practice takeoffs and landings - hence, maneuvers are hardly unlearned. It's rather more likely that they forget coordinated cooperation with the instruments in instrument flying. Also, motor skills and manual flying skills may degrade without training. Manual flying might be a little rough after some time of non-flying and a decrease in cognitive abilities may be a weaker point (see section above).

\section{Handover to / from Autopilot}

"The 'I hand over to the autopilot' is relatively simple. In modern planes this means 'Autopilot on'. That is, I press a button. The planned handover from the autopilot is also simple - I have a button on my yoke and press it."

Pilots, thereby, have a sort of interface that mediates between the autopilot and manual flying, i.e., the Flight Director. At the artificial horizon of the PFD, two lines are displayed which show exactly what the automatic or flight management would do. So, if pilots fly according to these lines and switch on the autopilot, it does exactly the same. Also, if the autopilot is switched off and pilots intend to fly according to the lines, then this also requires no big effort.

With regard to the decision of when to switch off the autopilot, the pilots argued that there are some situations in which it is simply easier to steer themselves. "You need to compare it a bit with cruise control of a car. I like to use it when there is little traffic on a freeway or highway, or even in the city with $30 \mathrm{~km} / \mathrm{h}$. But nobody would use it while parking."

In the case of an unplanned handover (i.e., the pilot switches the autopilot off because the plane does something the pilot does not want), it is important to have a plan in advance as the pilot will most be steering something, which is against the advice of the Flight Director.

In regards to the question of when unplanned handovers are likely to happen, it was pointed out that pilots are especially "alerted" when it comes to preparing later descent and landing. "In 99\% of the time or even more, it works very well, but not always and a certain skepticism is always appropriate." Pilots must have a plan in advance to make it work and if there is a deviation, the autopilot is either given a new mode or switched off and the pilot takes over. If, for example, certain actions to prepare for landing are done too late, the plane would be in an unstable state before the landing. In such a case, the only solution would be to touchand-go and try again. Regarding handovers back to the pilot due to evolving conditions, it was estimated that this happens in less than $1 \%$ of journeys.

\section{Critical Elements of Handovers from Autopilot to Pilot}

"There are often incidents, where pilots watched too long." Pilots use the autopilot frequently and the trust in the autopilot is generally high. This, however, can be dangerous, if the automatic system does not do what it should due to, e.g., a malfunction, sensory errors, wrong input by pilot, or wrong use of mode. In such cases, "pilots might even be aware that something is wrong, that the plane doesn't do what it should do, but nevertheless they waited - sometimes even until a crash." A further factor that might add to this is, when some pilots are probably also aware that they are less trained in manual flying and rely more on the autopilot. Therefore, it is very important to practice manual flying in a cruise flight, in order to know at any time "what the plane does, what it needs - you need to have it roughly in your head." Indeed, pilots frequently undertake training for situations where they need to switch off the autopilot and take over, because of a sensory error or technical outage.

In the case of any kind of error, the most important premise for pilots is to "first fly the aircraft." That is, basic flying is the most important (i.e., regulation of nose position, speed, altitude). Pilots need to bring the plane in a safe state first. Thereby the PFD (and in particular the artificial horizon) is in the main focus, apart from other displays that are relevant in that moment (e.g., regarding the engines). The analysis of what has happened or what the problem is, is done later. Thereby, the pilot and co-pilot share the work. While the one takes care of flying, the other tries to analyze and handle the problem.

\section{Changes in Skills/Routines by Autopilot Use}

The introduction of autopilots in the aviation domain had strong impact on the understanding of flying. "Flying meant earlier that you really needed to steer manually from $x$ to $y$, [...] Nowadays it's more about managing system procedures." Especially with regard to a wider definition of an autopilot (i.e., including the flight management and flight guidance behind it), there are different advantages and drawbacks. One advantage is that "pilots can move a 
bit backwards from direct flying. That's often not bad, because if you're not so much involved, you have a better overview." Also, using an autopilot allows pilots to relax to a certain degree - the autopilot mode can free up cognitive resources, hence, improving situation awareness. However, using an autopilot also means that pilots need to know what is behind the different modes, what is behind the system. As pointed out, even if the autopilot is switched off, the complex flight software behind it, is still active - hence, pilots need to know what happens in the background and why the system is doing certain things. Trainees need to be made aware that "just because they have pressed a button that the action has genuinely taken place, not just that the associated indicator has come on." Understanding what the autopilot does and what the different modes mean, is also part of pilots' trainings.

According to the flight instructors, a basic requirement for a good and reliable pilot is, naturally, a very good spatial orientation, and that $\mathrm{s} /$ he must not have a total deficit in any relevant core area (e.g., physics, mathematics, learning ability). Furthermore, teamwork is extremely important and pilots need to function in a team. Also, pilots must generally be a bit skeptical when approaching things. "If you face a situation, you need to generally assume that this could lead more to the negative side." Willingness to continue learning is also an important factor, even if pilots operate the same plane type for several years. Additionally, pilots should have a good flight sense, i.e., a certain feeling for the flying and how it influences the body. "In the past, it was said that planes are flown with the buttocks, because the instruments were more inaccurate." However, pilots must be aware that flight sense can also be deceived in certain situations.

\section{What can the Domain of Autonomous Driving learn from Automated Flying}

We also asked pilots what autonomous driving may learn from the aviation domain. "What you can learn from automated flying is that it comes easier to those, who always think along in normal mode." As outlined by the pilots, "thinking along" is an important aspect, i.e., even if semi-autonomous cars in the future may allow drivers to completely occupy themselves with other activities, "it would nevertheless be good to regularly occupy yourself with 'what if'." In line with pilots' experiences, drivers should be prepared, should have a concept of and be aware of what the automatic system is doing at any time.

Also, the aspect of situation awareness was mentioned. "Try to analyze the situation well and how it could develop in the worst case." The driver needs to be kept in the loop. Furthermore, it was suggested that drivers should "never have a poor or dangerous attitude." Hence, training of drivers should include an emphasis on responsibility. Also, developers must understand the need and level of interaction between man and machine. "If you don't understand how it works, it will come back to bite you".
Furthermore, pilots suggest distrusting the automatic system. "Even if it transported you safe and sound 99.9\% of the time, the software is likely not better than the one who programmed it." "The automatic functions are very, very reliable, very, very good, very, very sensitive as well, but not $100 \%$. A certain amount of distrust is always appropriate." Here, adequate simulator trainings, where malfunctions or sensory errors are simulated, could be helpful. Also, such simulator trainings could be used to avoid misuse of automated systems.

\section{DISCUSSION}

We now discuss the applicability of these results for autonomous driving and what AUI designers may learn for the interaction design of HMIs in semi-autonomous vehicles. Table 1 provides a comparison between findings from the pilot interviews and their potential effect on the automotive realm.

\section{Planning Ahead and Situation Awareness}

For the autonomous driving context, it might be worthwhile to consider automation systems in a similar way to airplane autopilots as assistance over long distances. Applying the shared driving concept [26], one could delegate different driving tasks to human and system even before the ride starts. On long motorway journeys, for example, it would be sensible to expect more need for driver involvement when exiting or entering the motorway. Thus, the system could calculate the expected points in time for motorway entry and exit in advance, so that the driver already knows when these segments will come up and when it will be required to be situationally aware. Similarly, difficult weather conditions could also increase necessary situation awareness (SA).

If such transition-relevant factors are communicated to the driver in advance instead of only in the moment, the driver can plan and adjust their SA in advance, allowing for both non-driving related tasks during low-SA phases, and readiness for transitions during high-SA phases.

The driver should also be able to plan ahead for not only regarding upcoming road environments, but also regarding driving mode characteristics (especially when only individual driving functions are automated), time taken to enable or disable these driving modes, and the time necessary to initiate and execute maneuvers after a transition. All of these decide how a driver of an autonomous vehicle can plan their cognitive attention throughout their journey.

\section{Transparency of System Status}

Safely operating a semiautonomous vehicle will likely require the availability of details on current driving modes, sensor functionality, and planned driving tasks for the driver. It is unlikely that the driver can be expected to monitor the vehicle at all times, as that would defeat many of the advantages of autonomous vehicle operation in the first place. However, it would be sensible to assume that the 
driver wants to verify correct vehicle operation at several points during a journey, in order to decide potential transition requirements ahead of time (not unlike, e.g., regularly checking the rearview mirrors while driving manually). If this information is available in a compact manner (i.e., all in one place), then transitions can be planned ahead of time with less cognitive involvement.

On the other hand, research and a discussion is needed on how much information about the functioning of the autonomous system in their car needs to be known by a driver. In the aviation example, pilots need to be aware of the fundamental principles. But pilots are, due to stricter regulations, almost always experts and drivers are often not. Thus, in the automotive domain, the granularity of information about the system to be shown to the driver still needs to be decided and adjusted for different levels of proficiency.

\section{Primary Drive Display}

Taking inspiration from the PFD and FMA in aviation, one efficient way to provide the right information in one place could be a primary drive display (PDD). Such a display could be used to inform the driver about the vehicle status and all other information related to driving environment and probability of necessary control transitions. Such a PDD can output standard status information constantly, which the driver can monitor at their own pace and output warnings or notifications in specific situations. Visualized information could include a navigation visualization (Where am I? How long to my destination? When is the next motorway exit? etc.). In case of a handover situation, the display could help the driver to raise situation awareness or even provide a checklist of actions (e.g., checking mirrors and verifying speed limit before confirming a transitions) the driver has to go through before taking over.

\section{Calibrated (Dis)Trust}

In line with the previous discussion points on enabling the driver to make informed decisions about transitions, the capabilities of a vehicle to perform certain actions or perceive hazards should also play an important role in such decisions. These require knowledge of which tasks an automated system is better suited for than a human, or in other words, when one should put more or less trust in the system to perform a task on its own and when delegation to or cooperation with a human would be recommended.

This potential for targeted trust or calibrated distrust has already been recognized [27, 28], but actual interface solutions for calibrated trust and distrust cues in an automated vehicle have not yet been implemented. Such solutions could be very helpful to increase situational driver readiness without necessarily reducing overall trust in automation [27].

\begin{tabular}{|c|c|}
\hline Aviation & Automotive \\
\hline $\begin{array}{l}\text { AP are always on. Only during } \\
\text { takeoff and landing is manual } \\
\text { flying is done. }\end{array}$ & $\begin{array}{l}\text { AV can be used for long- } \\
\text { distances (always on). Potential } \\
\text { to plan critical tasks (motorway } \\
\text { entry, exit, uneven roads, etc.) } \\
\text { for delegation to driver }\end{array}$ \\
\hline $\begin{array}{l}\text { AP differ between different } \\
\text { airplanes. Interaction with the } \\
\text { AP needs to be transparent. }\end{array}$ & $\begin{array}{l}\text { Interfaces in AV will be } \\
\text { different for different } \\
\text { manufacturers. Drivers needs to } \\
\text { know how to interact with } \\
\text { these. }\end{array}$ \\
\hline $\begin{array}{l}\text { AP can be operated on different } \\
\text { levels (e.g., descend for } \mathrm{x} \\
\text { meters vs. fly to a specific } \\
\text { destination.) }\end{array}$ & $\begin{array}{l}\text { AV should offer the automated } \\
\text { driving on a maneuvering and } \\
\text { strategical level. }\end{array}$ \\
\hline $\begin{array}{l}\text { Flying cannot be unlearned. A } \\
\text { good basic education is crucial. }\end{array}$ & $\begin{array}{l}\text { Driving cannot be unlearned. } \\
\text { Basic driving skills need to be } \\
\text { acquired (cf. [20]) }\end{array}$ \\
\hline $\begin{array}{l}\text { Flying with AP needs different } \\
\text { skills (e.g., orientation and } \\
\text { planning). }\end{array}$ & $\begin{array}{l}\text { Driving/riding in an AV will } \\
\text { require different skills than } \\
\text { driving manually. }\end{array}$ \\
\hline $\begin{array}{l}\text { Training of AP failures is } \\
\text { essential. }\end{array}$ & $\begin{array}{l}\text { Drivers should practice } \\
\text { handovers for critical system } \\
\text { failures. }\end{array}$ \\
\hline $\begin{array}{l}\text { APs are monitored regularly. } \\
\text { The pilot needs to get certain } \\
\text { information (e.g., position). }\end{array}$ & $\begin{array}{l}\text { Even in Level } 3 \text { or } 4 \\
\text { automation the driver will need } \\
\text { to monitor the AV. Basic } \\
\text { information needs to be } \\
\text { available all the time. }\end{array}$ \\
\hline $\begin{array}{l}\text { With AP, Primary Flight } \\
\text { Displays are used and scanning } \\
\text { patterns are trained. }\end{array}$ & $\begin{array}{l}\text { AV must be equipped with an } \\
\text { interface that allows the driver } \\
\text { to retrieve important } \\
\text { information with one glance. } \\
\text { Scanning patterns should be } \\
\text { trained to faster gain awareness } \\
\text { of the situation. }\end{array}$ \\
\hline $\begin{array}{l}\text { Flight Mode Annunciator } \\
\text { provides mode awareness on } \\
\text { different levels. }\end{array}$ & $\begin{array}{l}\text { When the AV has different } \\
\text { autonomy functions, these } \\
\text { should be made transparent for } \\
\text { the driver. }\end{array}$ \\
\hline $\begin{array}{l}\text { Pilots needs to undergo regular } \\
\text { checks of their abilities } \\
\text { (proficiency- and refresher } \\
\text { checks). }\end{array}$ & $\begin{array}{l}\text { Drivers needs to receive } \\
\text { adequate training for } \\
\text { driving/riding in an } \mathrm{AV} \text {. }\end{array}$ \\
\hline $\begin{array}{l}\text { Checklists are available for } \\
\text { specific procedures or errors. }\end{array}$ & $\begin{array}{l}\text { Checklists may be used to raise } \\
\text { situational awareness prior to } \\
\text { takeover procedures. }\end{array}$ \\
\hline $\begin{array}{l}\text { Distrust in the AP is } \\
\text { appropriate }\end{array}$ & $\begin{array}{l}\text { AV shall be designed to } \\
\text { provide the right level of trust. }\end{array}$ \\
\hline First fly the aircraft. & $\begin{array}{l}\text { In emergency handover } \\
\text { situations, it has to be clear for } \\
\text { the driver that taking over } \\
\text { manual control is most } \\
\text { important }\end{array}$ \\
\hline $\begin{array}{l}\text { The introduction of AP brought } \\
\text { a shift from manual flying to } \\
\text { managing. }\end{array}$ & $\begin{array}{l}\text { AV will bring a shift from } \\
\text { driving to managing the } \\
\text { vehicle. }\end{array}$ \\
\hline
\end{tabular}

$\mathrm{AP}=$ Autopilot, $\mathrm{AV}=$ Automated Vehicle

Table 1. Comparison between results from the aviation domain and their applicability for the automotive domain. 


\section{Training}

Contemporary pilot training accounts for the plane being a (partially) automated system. This is not yet the case for driver training. A driver is instructed how to actuate controls, perform maneuvers, stay situationally aware, and plan ahead when manually operating a vehicle. However, decisions about when to enable or disable assistance systems, capabilities of such systems, sensor capabilities under different weather conditions, different types of systems, how they are calibrated, enabled, disabled, and so on, are all part of operating an automated vehicle and not yet part of standard driver training. Therefore, if automated vehicles are to have the same status as manual vehicles in the everyday driving environment, then instruction on how to operate such vehicles needs to adapt to their additional capabilities and requirements.

In line with the issue of aforementioned issue of trust, capabilities of semi-autonomous vehicles and what they cannot provide need to be transparent. This also needs to be trained. For example, how does a semi-autonomous vehicle handle potential dangerous situations like, e.g., heavy rain? If the autonomous vehicle is not capable of dealing with such situations, the driver will need to practice such situations

\section{CONCLUSION}

In this paper, we have presented the findings from three indepth interviews with pilots and discussed the gained insights and implications for design of handovers in semiautonomous vehicles. Three pilots are not a representative sample to draw general conclusions from. Nevertheless, the interviews provided a homogenous view on how pilots interact with autopilots in the aviation domain and the in-depth nature of the interviews allowed for more detailed implications to be extracted for the automotive domain. Results show that not everything that works for aviation can be applied to the automotive domain. Pilots are highly trained individuals. A comparable level of training can hardly be expected to be reached by all vehicle drivers, who span a wide spectrum of driving frequency and expertise.

Nonetheless, due to the conceptual similarity of piloting modern aircraft and semiautonomous driving, there are several aspects, which can conceivably be adapted for the automotive domain. We can conclude that insights on planning ahead and situation awareness, the transparency of system status, the need for a primary drive display, calibrated (dis)trust, and driver training may all be successfully transferred from aviation to the automotive domain to inspire safe and efficient handover design.

\section{ACKNOWLEDGMENTS}

The financial support by the Austrian Science Fund (FWF): I 2126-N15 is gratefully acknowledged. The financial support of the Fonds National de La Recherche, Luxembourg under grant number: CS14/IS/8301419.

\section{REFERENCES}

1. Kasey A. Ackerman, Enric Xargay, Donald A. Talleur, Ronald S. Carbonari, Alex Kirlik, Naira Hovakimyan, Irene M. Gregory, Christine M. Belcastro, Anna Trujillo, and Benjamin D. Seefeldt. 2015. Flight Envelope Information-Augmented Display for Enhanced Pilot Situational Awareness. In AIAA Infotech@Aerospace.1112.DOI: http://arc.aiaa.org/doi/abs/10.2514/6.2015-1112.

2. Kasey A. Ackerman, Donald A. Talleur, Ronald S. Carbonari, Enric Xargay, Benjamin D. Seefeldt, Alex Kirlik, Naira Hovakimyan, and Anna C. Trujillo. 2017. Automation Situation Awareness Display for a Flight Envelope Protection System. Journal of Guidance, Control, and Dynamics 40, 4 (April 2017), 964-980. DOI: http://dx.doi.org/10.2514/1.G000338.

3. Haitham Baomar and Peter J. Bentley. 2016. An Intelligent Autopilot System that learns piloting skills from human pilots by imitation. In Unmanned Aircraft Systems (ICUAS), 2016 International Conference on. IEEE, 1023-1031. http://ieeexplore.ieee.org/abstract/document/7502578/.

4. Virginia Braun and Victoria Clarke. 2006. Using Thematic Analysis in Psychology. Qualitative Research in Psychology, 3(2), 77-101.

5. Joan Cahill, Tiziana C Callari, Florian Fortmann, Denis Javaux, and Andreas Hasselberg. 2016. A-PiMod: A New Approach to Solving Human Factors Problems with Automation. In Engineering Psychology and Cognitive Ergonomics, Don Harris (Ed.). Vol. 9736. Springer International Publishing, Cham, 269-279. DOI: 10.1007/978-3-319-40030-3_27.

6. Bureau d'Enquetes et d'Analyses France (BEA). 2014. Final Report: Accident to Airbus A330-203 registered F-GZCP, Air France AF 447 Rio de Janeiro - Paris, 1st June 2009. Technical Report. Ministère de l'Écologie, du Développementdurable, des Transports et du Logement.

7. Kelly Funkhouser and Frank Drews. 2016. Reaction Times When Switching From Autonomous to Manual Driving Control: A Pilot Investigation. Proceedings of the Human Factors and Ergonomics Society Annual Meeting 60, 1 (Sept. 2016), 1854-1858. DOI: http://dx.doi.org/10.1177/1541931213601423.

8. Christian Gold, Daniel Damböck, Lutz Lorenz, and Klaus Bengler. 2013. "Take over!" How long does it take to get the driver back into the loop? Proceedings of the Human Factors and Ergonomics Society Annual Meeting 57, 1 (2013), 1938-1942. DOI: http://dx.doi.org/10.1177/1541931213571433.

9. Jamison S. Hicks, David B. Durbin, Anthony W. Morris, and Brad M. Davis. 2014. A Summary of Crew Workload and Situational Awareness Ratings for US 
Army Aviation Aircraft. Technical Report. DTIC Document. http://oai.dtic.mil/oai/oai?verb=getRecord\& metadataPrefix $=$ html\&identifier $=$ ADA606506.

10. Swedish Disaster Medicine Study Organisation (Kamedo). 1994. Air traffic accident at Gottröra, Sweden December 27, 1991 - KAMEDO-report 63. Technical Report. National Board of Health and Welfare.

11. Catherine Letondal, Julien Castet, Jean-Luc Vinot, Jean-Baptiste De La Rivière, and Sylvain Pauchet. 2014. Exploring the Physical Design Space for Situation Awareness and Performance in the Interactive Cockpit. In TEI 2014, 8th International Conference on Tangible, Embedded and Embodied Interaction. https://hal- enac.archives- ouvertes.fr/hal00943498.

12. Jerry Marstall, Michael E. Miller, and Robert J. Poisson. 2016. Collaboration in the Cockpit: HumanSystem Interaction Beyond the Autopilot. Ergonomics in Design: The Quarterly of Human Factors Applications 24, 1 (Jan. 2016), 4-8. DOI: http://dx.doi.org/10.1177/1064804615572628.

13. Alexander Meschtscherjakov, Rod McCall, Nicolas Louveton, Thomas Engel, Manfred Tscheligi, and Vincent Koenig. 2015. MaDSAV: maintaining driving skills in semi-autonomous vehicles. In Adjunct Proceedings of the 7th International Conference on Automotive User Interfaces and Interactive Vehicular Applications (AutomotiveUI '15). ACM, New York, NY, USA, 136-139. DOI: http://dx.doi.org/10.1145/2809730.2809732.

14. Nadine M. Moacdieh, Julie C. Prinet, and Nadine B. Sarter. 2013. Effects of Modern Primary Flight Display Clutter: Evidence from Performance and Eye Tracking Data. Proceedings of the Human Factors and Ergonomics Society Annual Meeting 57, 1 (Sept. 2013), 11-15. DOI: http://dx.doi.org/10.1177/1541931213571005.

15. Raja Parasuraman and Victor Riley. 1997. Humans and Automation: Use, Misuse, Disuse, Abuse. Human Factors: The Journal of the Human Factors and Ergonomics Society 39, 2 (Jun 1997), 230-253. DOI: http://dx.doi.org/10.1518/001872097778543886.

16. Raja Parasuraman, Thomas B. Sheridan, and Christopher D. Wickens. 2008. Situation Awareness, Mental Workload, and Trust in Automation: Viable, Empirically Supported Cognitive Engineering Constructs. Journal of Cognitive Engineering and Decision Making 2, 2 (June 2008), 140-160. DOI: http://dx.doi.org/10.1518/155534308X284417.

17. Paul M. Salmon, Guy H. Walker, and Neville A. Stanton. 2016. Pilot error versus sociotechnical systems failure: a distributed situation awareness analysis of Air France 447. Theoretical Issues in Ergonomics Science 17, 1 (Jan. 2016), 64-79. DOI: http://dx.doi.org/10.1080/1463922X.2015.1106618.

18. Lance Sherry and Robert Mauro. 2014. Controlled flight into stall (CFIS): Functional complexity failures and automation surprises. In Integrated Communications, Navigation and Surveillance Conference (ICNS), 2014. IEEE, D1-1. http://ieeexplore.ieee.org/abstract/document/6819980.

19. United States. 1996. In-flight icing encounter and loss of control, Simmons Airlines, d.b.a. American Eagle flight 4184, Avions de Transport Regional (ATR) model 72-212, N401AM, Roselawn, Indiana, October 31, 1994 [electronic resource] / National Transportation Safety Board. National Transportation Safety Board Washington, D.C.

20. Sandra Trösterer, Magdalena Gärtner, Alexander Mirnig, Alexander Meschtscherjakov, Rod McCall, Nicolas Louveton, Manfred Tscheligi, and Thomas Engel. 2016. You Never Forget How to Drive: Driver Skilling and Deskilling in the Advent of Autonomous Vehicles. In Proceedings of the 8th International Conference on Automotive User Interfaces and Interactive Vehicular Applications (Automotive'UI 16). ACM, New York, NY, USA, 209-216. DOI: https://doi.org/10.1145/3003715.3005462.

21. Hidde van der Meulen, Andrew L. Kun, and Christian P. Janssen. 2016. Switching Back to Manual Driving: How Does it Compare to Simply Driving Away After Parking? ACM Press, 229-236. DOI: http://dx.doi.org/10.1145/3003715.3005452.

22. Mark S. Young, Neville A. Stanton, and Don Harris. 2007. Driving automation: learning from aviation about design philosophies. International Journal of Vehicle Design 45, 3 (Jan. 2007), 323-338. DOI: http://dx.doi.org/10.1504/IJVD.2007.014908.

23. SAE International, "Operational Definitions of Driving Performance Measures and Statistics", SAE Standard J2944 (proposed draft), 2016.

24. Roderick McCall, Fintan McGee, Alexander Meschtscherjakov, Nicolas Louveton, and Thomas Engel. 2016. Towards A Taxonomy of Autonomous Vehicle Handover Situations. In Proceedings of the 8th International Conference on Automotive User Interfaces and Interactive Vehicular Applications (Automotive'UI 16). ACM, New York, NY, USA, 193-200. DOI: https://doi.org/10.1145/3003715.3005456.

25. Leo J. Gugerty. 1997. Situation awareness during driving: Explicit and implicit knowledge in dynamic spatial memory. Journal of Experimental Psychology: Applied 3, 1: 42-66. DOI: http://doi.org/10.1037/1076898X.3.1.42. 
26. Klaus Bengler, Klaus Dietmayer, Berthold Farber, Markus Maurer, Christoph Stiller, and Hermann Winner. 2014. Three Decades of Driver Assistance Systems: Review and Future Perspectives. IEEE Intelligent Transportation Systems Magazine 6, 4, 622. DOI:

http://dx.doi.org/10.1109/MITS.2014.2336271.

27. Alexander G. Mirnig, Philipp Wintersberger, Christine Sutter, and Jürgen Ziegler. 2016. A Framework for Analyzing and Calibrating Trust in Automated Vehicles. In Adjunct Proceedings of the 8th International Conference on Automotive User Interfaces and Interactive Vehicular Applications (AutomotiveUI '16 Adjunct). ACM, New York, NY, USA, 33-38. DOI:

https://doi.org/10.1145/3004323.3004326

28. Ewart J. Visser, Marvin Cohen, Amos Freedy, and Raja Parasuraman. 2014. A Design Methodology for Trust Cue Calibration in Cognitive Agents. In Proceedings, Part I, of the 6th International Conference on Virtual, Augmented and Mixed Reality. Designing and Developing Virtual and Augmented Environments - Volume 8525, Randall Shumaker and Stephanie Lackey (Eds.), Vol. 8525. Springer-Verlag New York, Inc., New York, NY, USA, 251-262. DOI: http://dx.doi.org/10.1007/978-3-319-07458-0_24. 